\title{
Análise da variabilidade genética de populações de Helicoverpa armigera (Lepidoptera: noctuidae) ocorrendo em culturas de algodão e tomate
}

\author{
Paulo Roberto Queiroz ${ }^{1}$ \\ Luzia Helena Corrêa Lima²
}

\section{Resumo}

Helicoverpa armigera é uma das principais pragas polífagas de distribuição mundial das culturas de interesse econômico. A identificação dessa espécie por meio molecular auxilia no estabelecimento do perfil genético, na caracterização e no monitoramento das populações desse inseto da ordem Lepidoptera. O objetivo desse trabalho foi estabelecer uma metodologia de extração de DNA para H. armigera, determinar perfis eletroforéticos e analisar a variabilidade genética entre as populações desse inseto-praga. Os cinco iniciadores de RAPD produziram fragmentos de DNA que revelaram uma similaridade genética inferior a $80 \%$ entre as dez populações no dendrograma que foi gerado. Os resultados obtidos com as análises de variância molecular (AMOVA) revelaram que a elevada fonte de variação genética foi o resultado da variabilidade dentro de cada população. As causas que levaram a essa elevada variabilidade precisam ser mais bem estudadas nos países onde a praga ocorre.

Palavras-chave: Marcador molecular. RAPD. Tomate. Algodão.

\section{Introdução}

As espécies de insetos da ordem Lepidoptera podem ser pragas específicas de determinadas plantas hospedeiras, assim como, atacar plantas de gêneros ou de

1 PhD Biologia Animal. Universidade de Brasília - UnB. Professor do curso de Biomedicina UniCEUB; e-mail: pqsilva@uol.com.br

2 PhD Biologia Molecular. Universidade de Brasília - UnB. Pesquisadora da Embrapa Recursos Genéticos e Biotecnologia; e-mail: luzia@cenargen.embrapa.br 
famílias botânicas variadas. As injúrias causadas por esses insetos são provocadas pela fase de larva e pode-se citar a formação de minas no parênquima foliar, desfolha, perfurações de caule e raiz, destruição das estruturas foliares, sementes e frutos (HOLLOWAY; BRADLEY; CARTER, 1987; PAULA et al., 2004).

A determinação das espécies de Lepidoptera baseia-se na análise dos caracteres morfológicos. Entretanto, outras estratégias podem ser utilizadas na identificação, tais como, a análise molecular. Essas são ferramentas úteis que auxiliam no estabelecimento do perfil genético dos insetos, caracterização e identificação de marcadores que sejam específicos para populações de lepidópteras de interesse quarentenário.

Dessa forma, a técnica de RAPD (WILLIAMS et al., 1990) tem sido muito utilizada por apresentar características que permitem a obtenção de um grande número de informações para a análise de genomas pouco conhecidos em termos de composição, uma vez que emprega a utilização de um único iniciador de sequência arbitrária com potencial de reconhecer regiões desconhecidas do DNA alvo. Os marcadores RAPD se baseiam na amplificação do DNA, gerando informações com simplicidade e rapidez a baixos custos. Assim, grande quantidade de polimorfismo, na forma de segmentos de DN é obtida em curto espaço de tempo (FERREIRA; GRATTAPAGLIA, 1998). Uma característica desse tipo de marcador é o seu comportamento como genético dominante. Lembrando que a dominância, nesse caso, não se refere à interação genética entre alelos de um mesmo locus e sim à interpretação relativa entre fenótipo e genótipo (CIAMPI; MAGALHÃES, 2001).

Os marcadores RAPD tem sido utilizados na análise molecular de espécies de lepidópteras, tais como, Anticarsia gemmatalis (SOSA-GÓMEZ, 2004), Plutella xylostela (MARTINS et al., 2005) e S. frugiperda (NAGOSHI; MEAGHER, 2008). 
A identificação e a diagnose correta das espécies dessa ordem são essenciais na elaboração de estratégias para o controle de pragas. Helicoverpa armigera (Lepidoptera: Noctuidae) é uma praga polífaga de importantes culturas de interesse agronômico. Os indivíduos maturos alimentam-se em todos os estágios de desenvolvimento da planta, danificando as estruturas frutíferas e não frutíferas (JOHNSON; ZALUCKI, 2005). As larvas dessa espécie atacam ramos, flores e cápsulas da semente de plantas desenvolvidas (SANNINO, 2005). Essa praga se alimenta das partes da planta que são de maior valor para o consumo humano, provocando reduções na quantidade de alimentos disponíveis. Por exemplo, as perdas anuais na produção de feijão-guandu provocadas por $H$. armigera são estimadas em U\$ 317 milhões no mundo todo (SHANOWER et al., 1999).

\section{Objetivo}

Estabelecer uma metodologia de extração de DNA para H. armigera, visando determinar perfis eletroforéticos para essa praga exótica e analisar a variabilidade genética entre larvas desse inseto coletadas em culturas de algodão e tomate em quatro localidades de Burkina Faso, África.

\section{Material e métodos}

\subsection{Insetos}

Larvas de $H$. armigera encontradas nas culturas de algodão e tomate provenientes das localidades de Soumousso, N’Dorola, Gaoua e Réo em Burkina Faso foram coletadas pela técnica de pano de batida, armazenadas em etanol $95 \%$ a $4{ }^{\circ} \mathrm{C}$ e submetidas a identificação molecular (Tabela 1). 
Tabela 1. Indivíduos de H. armigera coletados em culturas de algodão e tomate em quatro localidades de Burkina Faso e utilizados nos experimentos de identificação molecular.

\begin{tabular}{|c|c|c|c|c|}
\hline Amostra & $\begin{array}{l}\text { Data de } \\
\text { coleta }\end{array}$ & Cultura & $\begin{array}{l}\text { Província de } \\
\text { Burkina Faso }\end{array}$ & $\begin{array}{l}\text { Localização } \\
\text { geográfica }\end{array}$ \\
\hline AlSo1 & $\begin{array}{c}7 \text { de setembro } \\
\text { de } 2001\end{array}$ & Algodão & Soumousso & \multirow{3}{*}{$\begin{array}{l}11^{\circ} 1^{\prime} 0^{\prime \prime} \text { North, } \\
4^{\circ} 3^{\prime} 0^{\prime \prime} \text { West. }\end{array}$} \\
\hline AlSo2 & $\begin{array}{c}11 \mathrm{de} \\
\text { novembro de } \\
2001\end{array}$ & Algodão & Soumousso & \\
\hline ToSo3 & $\begin{array}{l}7 \text { de janeiro } \\
\text { de } 2002\end{array}$ & Tomate & Soumousso & \\
\hline AlND4 & $\begin{array}{c}6 \text { de setembro } \\
\text { de } 2001\end{array}$ & Algodão & N'Dorola & \multirow{3}{*}{$\begin{array}{c}11^{\circ} 25^{\prime} 0^{\prime \prime} \text { North, } \\
5^{\circ} 0^{\prime} 0^{\prime \prime} \text { West }\end{array}$} \\
\hline AlND5 & $\begin{array}{c}13 \mathrm{de} \\
\text { novembro de } \\
2001\end{array}$ & Algodão & N'Dorola & \\
\hline ToND6 & $\begin{array}{l}17 \text { de janeiro } \\
\text { de } 2002\end{array}$ & Tomate & N’Dorola & \\
\hline AlGa7 & $\begin{array}{l}12 \text { de outubro } \\
\text { de } 2001\end{array}$ & Algodão & Gaoua & \multirow{2}{*}{$\begin{array}{c}10^{\circ} 19^{\prime} 0 \text { " North, } \\
3^{\circ} 10^{\prime} 0^{\prime \prime} \text { West }\end{array}$} \\
\hline ToGa8 & $\begin{array}{l}25 \text { de janeiro } \\
\text { de } 2002\end{array}$ & Tomate & Gaoua & \\
\hline AlRe9 & $\begin{array}{l}12 \text { de outubro } \\
\text { de } 2001\end{array}$ & Algodão & Réo & \multirow{2}{*}{$\begin{array}{c}12^{\circ} 19^{\prime} 0^{\prime \prime} \text { North, } \\
2^{\circ} 28^{\prime} 0^{\prime \prime} \text { West }\end{array}$} \\
\hline ToRe10 & $\begin{array}{l}24 \text { de janeiro } \\
\text { de } 2002\end{array}$ & Tomate & Réo & \\
\hline
\end{tabular}

\subsection{Obtenção de ácidos nucleicos}

Para a obtenção dos ácidos nucleicos totais, utilizou-se a metade posterior de cinco larvas de terceiro ínstar de indivíduos de H. armigera que foram coletados em cada uma das várias localidades de Burkina Faso. Essas amostras foram submetidas à extração de DNA (QUEIROZ et al., 2004) adicionando-se $500 \mu \mathrm{L}$ de tampão de extração (Tris-HCl 10 mM pH 8, EDTA 1 mM, Triton X-100 0,3\% e Proteinase $\mathrm{K} 120 \mu \mathrm{g} . \mathrm{mL}^{-1}$ ) e incubando-se por $60 \mathrm{~min}$ a $65^{\circ} \mathrm{C}$. O homogenato foi centrifugado por $10 \mathrm{~min}$ a $10.000 \times \mathrm{g}$ e, o sobrenadante, transferido para um novo tubo plástico de 1,5 mL. Adicionou-se $500 \mu \mathrm{L}$ de fenol/clorofórmio/álcool 
isoamílico (25:24:1) e as fases foram homogeneizadas em vortex por $30 \mathrm{~s}$. O material foi centrifugado por $10 \mathrm{~min}$ a $10.000 \times \mathrm{g}$ a $10^{\circ} \mathrm{C}$. A fase aquosa foi então transferida para um novo tubo plástico de $1,5 \mathrm{~mL}$, repetindo-se o tratamento com $500 \mu \mathrm{L}$ de fenol/clorofórmio/álcool isoamílico.

O DNA foi precipitado pela adição de $30 \mu \mathrm{L}$ de $\mathrm{NaCl} 5 \mathrm{M}$ e $1 \mathrm{~mL}$ de etanol absoluto incubando-se por $2 \mathrm{~h}$ a $-20^{\circ} \mathrm{C}$. Após centrifugação a $10.000 x \mathrm{~g}$ por 10 min a $10^{\circ} \mathrm{C}$, o DNA precipitado foi lavado duas vezes com $500 \mu \mathrm{L}$ de etanol $70 \%$, seco, ressuspenso em tampão TE 0,1X (Tris- $\mathrm{HCl} 1 \mathrm{mM} \mathrm{pH} \mathrm{8,} \mathrm{EDTA} \mathrm{0,1} \mathrm{mM)} \mathrm{e}$ armazenado a $-20^{\circ} \mathrm{C}$.

Para as análises moleculares, utilizou-se o DNA diluído em tampão TE 0,1X para se obter uma concentração final de $20 \mathrm{ng} \cdot \mu \mathrm{L}^{-1}$.

\subsection{Reações de RAPD}

Para os estudos de identificação molecular, o DNA extraído de cada uma das amostras foi utilizado em $30 \mu \mathrm{L}$ de uma reação contendo tampão Tris- $\mathrm{HCl} 6$ $\mathrm{mM}$ (pH 8,8), KCl 50 mM, $\mathrm{MgCl}_{2} 2$ mM, dNTP's 0,2 mM, 0,4 $\mu \mathrm{M}$ de um oligonucleotídio de sequência aleatória da Operon Technologies, Inc.(Tabela 2), 2,5 U. $\mu \mathrm{L}^{-1}$ de Taq DNA polimerase (Amersham Health Care) e $5 \mu \mathrm{L}$ de DNA (20 ng. $\left.\mu \mathrm{L}^{-1}\right)$.

Tabela 2. Iniciadores decaméricos utilizados nas reações de RAPD para a identificação molecular de H. armigera.

\begin{tabular}{ll}
\hline Iniciador & Sequência $\left(5^{\prime} \rightarrow 3^{\prime}\right)$ \\
\hline OPA-02 & TGC CGA GCT G \\
OPA-03 & AGT CAG CCA C \\
OPA-04 & AAT CGG GCT G \\
OPA-10 & GTG ATC GCA G \\
OPA-13 & CAG CAC CCA C
\end{tabular}




\subsection{Ciclos de amplificação}

As amplificações foram efetuadas em termociclador (PTC 100 MJ Research) programado para 45 ciclos, contendo uma etapa inicial de desnaturação de 3 min a $94^{\circ} \mathrm{C}$. Cada ciclo foi constituído de uma etapa de desnaturação de $1 \mathrm{~min}$ a $93^{\circ} \mathrm{C}$, anelamento por 1 min a $35^{\circ} \mathrm{C}$ e extensão por 2 min a $72^{\circ} \mathrm{C}$. Após os ciclos, foi realizada uma etapa de extensão final de $5 \min$ a $72^{\circ} \mathrm{C}$.

\subsection{Obtenção de perfis eletroforéticos}

Os produtos de amplificação foram visualizados em gel de agarose 1,5\% submerso em tampão TBE $1 X$ (Tris-borato 9 mM e EDTA $1 \mathrm{mM}$ ), fotografados e arquivados no sistema Eagleeye. Em todos os géis, marcadores de massa molecular (Leader 100 bp - GIBCO) foram usados para a determinação do tamanho dos fragmentos amplificados.

\subsection{Análise dos dados}

As fotos das amplificações com os vários oligonucleotídios foram usadas para a análise do polimorfismo entre os indivíduos de uma mesma população e entre as populações em estudo. Os fragmentos de DNA presentes nos géis foram considerados como marcadores RAPD. Foi gerada, então, uma matriz de similaridade, levando-se em consideração a relação entre indivíduo, iniciador e massas moleculares dos fragmentos obtidos com um dado iniciador. Utilizou-se como padrão o valor 1 para a presença de um marcador. Na ausência de marcador, atribuiu-se o valor 0. No caso de dúvida, o número 9 foi usado como padrão. A seguir, a planilha obtida foi submetida a um programa de análise estatística multivariada para a determinação das similaridades entre os indivíduos. O programa usado foi o NTSYS-pc versão 2.02 (RHOLF, 1993) e teve como função a análise estatística multivariada de diferentes análises com matrizes de similaridade. A matriz de similaridade e agrupamento para essa análise foi feita por UPGMA (Unweighted 
PairGroup Method, Arithmetic Average), agrupando os indivíduos par a par e determinando um dendrograma.

A seguir, os valores obtidos e tabelados em uma planilha foram submetidos à análise de variância molecular (AMOVA) para a determinação estatística das possíveis origens das variabilidades encontradas nas populações pela aplicação de algoritmos específicos pelo programa Arlequin ver. 2000 (SCHNEIDER; ROESSLI; EXCOFFIER, 2000).

\subsection{Resultados}

\subsubsection{Extração de DNA e reações de RAPD}

O sucesso na obtenção de marcadores moleculares via RAPD é dependente da qualidade do DNA obtido a partir dos tecidos do inseto. A técnica de extração de DNA que foi adaptada para esse trabalho forneceu DNA com quantidade (em torno de 1 $\left.\mu g . \mu \mathrm{L}^{-1}\right)$ e qualidade $(260 \mathrm{~nm} / 280 \mathrm{~nm}=0,8)$ para analisar a variabilidade genética de dez populações de $H$. armigera, utilizando-se apenas cinco iniciadores de RAPD.

Os vários iniciadores de RAPD produziram 61 fragmentos de amplificação com uma média de 12,2 \pm 5,2 fragmentos por oligonucleotídio. Os iniciadores OPA03 e OPA-13 produziram 15 fragmentos de DNA, seguindo-se os iniciadores OPA02 e OPA-10 com 14 fragmentos. O iniciador OPA-04 gerou apenas 4 fragmentos.

Analisando-se os 61 fragmentos gerados pela técnica de RAPD, observou-se que apenas 2 fragmentos (3,28\%) foram isomórficos e 59 (96,72\%) foram polimórficos.

Em seguida, analisou-se a contribuição de cada iniciador de RAPD para revelar a variabilidade genética de cada população de $H$. armigera analisada neste estudo (Figura 1). 
Figura 1 - Distribuição dos fragmentos gerados pelos cinco iniciadores de RAPD em dez populações de $\mathrm{H}$. armigera coletadas em culturas de algodão e tomate em três localidades de Burkina Faso. Os códigos indicam: AlSo1, Algodão Soumousso 1; AlSo2, Algodão Soumousso 2; ToSo3, Tomate Soumousso 3; AlND4, Algodão N’Dorola 4; AlND5, Algodão N’Dorola 5; ToND6, Tomate N’Dorola 6; AlGa7, Algodão Gaoua 7; ToGa8, Tomate Gaoua 8; AlRe9, Algodão Réo 9; ToRe10, Tomate Réo 10.
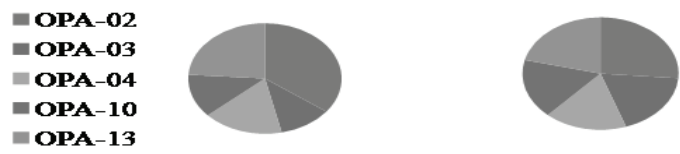

Also1

ToND6
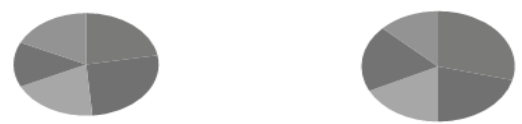

AlSo2

AlGa 7
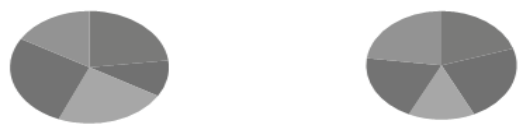

ToGa8
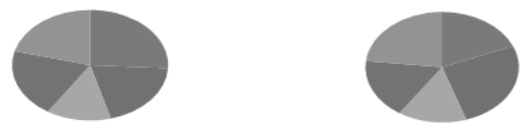

AlRe9

AIND4

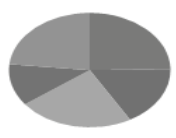

AIND5

ToRe10

O iniciador OPA-02 gerou o maior número de fragmentos de RAPD para as populações de $H$. armigera provenientes de culturas de algodão de Soumousso (AlSo1), 35,2\%, algodão de N’Dorola (ALND4), 25,9\%, tomate de N’Dorola (ToND6) 26,3\%, algodão de Gaoua (AlGa7), 29,0\% e tomate de Réo (ToRe10), 24,7\%. Em seguida, o oligonucleotídio OPA-03, com 26,4\% para a população proveniente da cultura de algodão de Soumousso (AlSo2), tomate de Gaoua (ToGa8), com 22,9\% e algodão de Réo (AlRe9), com 26,1\%.

Observou-se ainda que o oligonucleotídio OPA-04 gerou o maior número de fragmentos de RAPD por população, ou seja, 42,4\% para a amostra proveniente da cultura de algodão de N’Dorola (AlND4). 
Por sua vez, o iniciador OPA-03 produziu o menor número de fragmentos de RAPD por população, ou seja, apenas para a população proveniente de tomate de Soumousso (ToSo3) com 10,3\%.

A partir dessas informações, foi possível determinar que os iniciadores OPA-02 e OPA-03 contribuíram com 80\% dos fragmentos gerados pela técnica de RAPD para as populações analisadas neste estudo.

\subsubsection{Identificação molecular de H. armigera por RAPD}

A partir da adaptação da metodologia de extração de DNA para H. armigera, foram obtidos diferentes perfis eletroforéticos entre os indivíduos analisados, utilizando-se os cinco iniciadores nas reações de RAPD. Empregando-se o iniciador OPA-02 nas reações de amplificação, observaram-se diferentes perfis moleculares entre os indivíduos de uma mesma população, como também, entre populações distintas (Figuras 2 e 3).

Figura 2 - Perfis eletroforéticos de H. armigera obtidos com o iniciador OPA-02. Os números indicam: 1 a 5, tomate em N'Dorola; 6 a 10, algodão em Gaoua; 11 a 15, tomate em Gaoua; 16 a 20, algodão em Réo; 21 a 23, tomate em Réo. A letra M indica o marcador de massa molecular $100 \mathrm{pb}$ ladder.

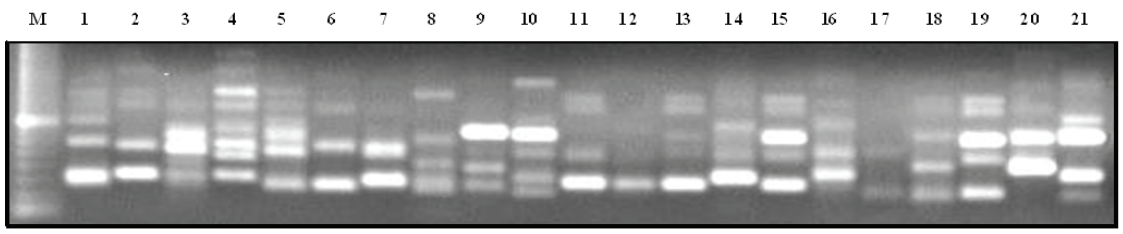

Figura 3 - Perfis eletroforéticos de H. armigera obtidos com o iniciador OPA-02. Os números indicam: 1 a 5, algodão em Soumousso; 6 a 10, algodão em Soumosso; 11 a 15, tomate em Soumosso; 16 a 20, algodão em N'Dorola, e 21, algodão em N'Dorola. A letra M indica o marcador de massa molecular 100 pb ladder.

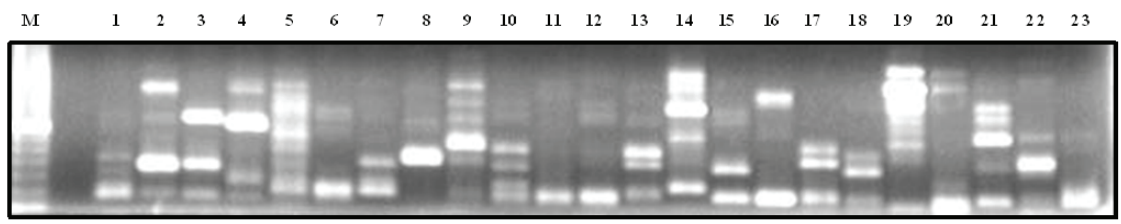


Empregando-se o oligonucleotídio OPA-02 não foi possível identificar qualquer padrão isomórfico entre os indivíduos dessa espécie. Contudo, a utilização desse iniciador revelou a variabilidade genética existente entre as populações de $H$. armigera analisadas neste estudo.

Resultado diferente foi obtido com o oligonucleotídio OPA-10, no qual foram identificados dois fragmentos isomórficos em todas as populações de H. armigera analisadas. (Figuras 4 e 5).

Figura 4 - Perfis eletroforéticos de H. armigera obtidos com o oligonucleotídio OPA-10. Populações coletadas de: 1 a 5, tomate em N’Dorola; 6 a 10, algodão em Gaoua; 11 a 15, tomate em Gaoua; 16 a 20, algodão em Réo; 21 a 23, tomate em Réo. A letra M indica o marcador de massa molecular $100 \mathrm{pb}$ ladder. As setas indicam os fragmentos de $500 \mathrm{pb}$ e de 850 pb.

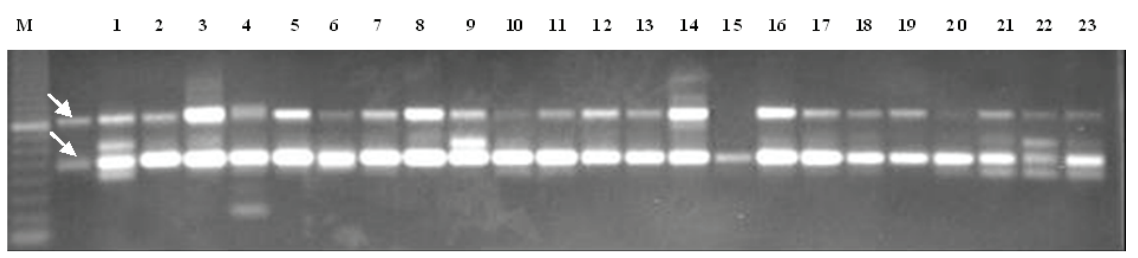

Figura 5 - Perfis eletroforéticos de H. armigera obtidos com o oligonucleotídio OPA-10. Populações coletadas de: 1 a 5, algodão em Soumousso; 6 a 10, algodão em Soumosso; 11 a 15, tomate em Soumosso; 16 a 20, algodão em N’Dorola, e 21, algodão em N’Dorola. A letra $\mathrm{M}$ indica o marcador de massa molecular $100 \mathrm{pb}$ ladder. As setas indicam os fragmentos de $500 \mathrm{pb}$ e de $850 \mathrm{pb}$.

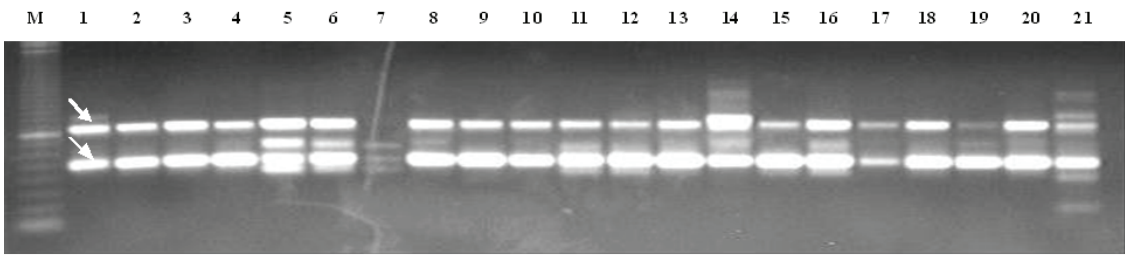

O uso do iniciador OPA-10 nas reações de amplificação por RAPD produziu fragmentos de 500 pb e de 850 pb, que foram identificados nos indivíduos de todas as populações de $H$. armigera recebidas para a determinação dos perfis eletroforéticos de RAPD. Os fragmentos de DNA gerados pelo iniciador OPA-10 
apresentam potencial para o desenvolvimento de marcadores específicos para a identificação dessa espécie a partir de populações coletadas em diferentes plantas hospedeiras e/ou regiões geográficas.

Para os demais oligonucleotídios, observou-se uma variação no padrão de marcadores RAPD entre os indivíduos. Contudo, mesmo com a utilização de poucos iniciadores, foi possível identificar polimorfismos entre os indivíduos analisados. A partir dessa informação, o polimorfismo produzido por cada organismo foi então utilizado para a determinação da matriz de distância genética (Figura 6).

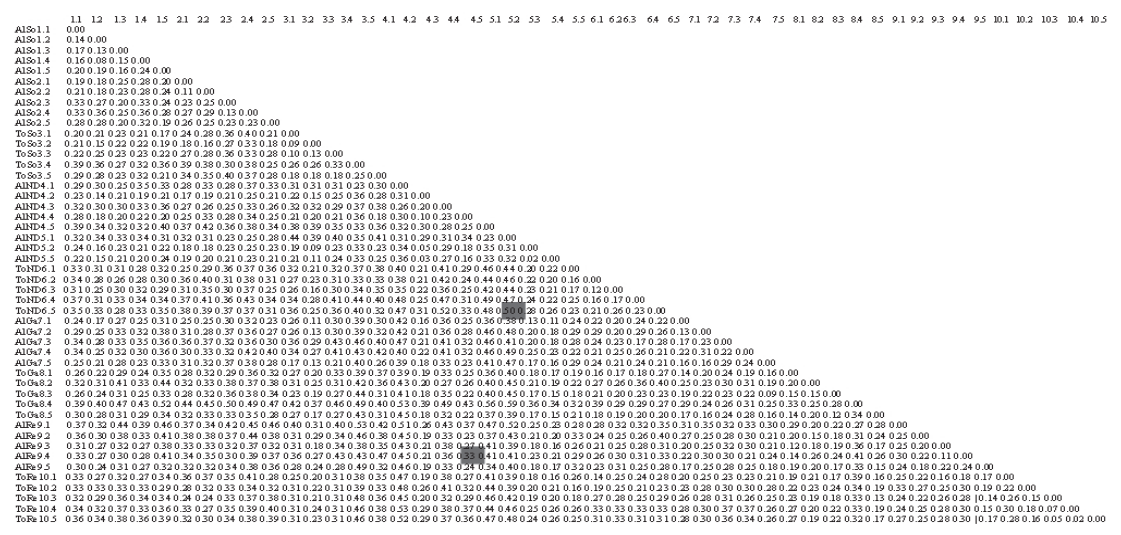

Figura 6 - Matriz de distância genética entre os indivíduos de dez populações de $\mathrm{H}$. armigera. Os códigos indicam: AlSo1, Algodão Soumousso; AlSo2, Algodão Soumousso; ToSo3, Tomate Soumousso; AlND4, Algodão N'Dorola; AlND5, Algodão N’Dorola; ToND6, Tomate N’Dorola; AlGa7, Algodão Gaoua; ToGa8, Tomate Gaoua; AlRe9, Algodão Réo; ToRe10, Tomate Réo. Em vermelho estão indicados o maior e o menor índice de distância genética entre os indivíduos analisados nesse estudo.

A partir da organização dos dados binários produzidos pelos marcadores RAPD, obteve-se a matriz de distância genética entre os vários indivíduos analisados. A distância genética variou de 2\%, entre os indivíduos AlND5. 3 e AlND5.5, pertencentes a uma mesma população coletada na cultura de algodão em N’Dorola; a 56\%, entre os indivíduos ToGa8.4 e AlND5.1, originários de populações coletadas em tomate (Gaoua) e algodão (N’Dorola). A partir dessas informações, observou-se uma elevada variabilidade genética entre as populações em análise. 
A seguir, os dados binários correspondentes aos vários indivíduos foram utilizados para a determinação de um dendrograma para o estabelecimento das relações filogenéticas entre as dez populações de $H$. armigera (Figura 7).

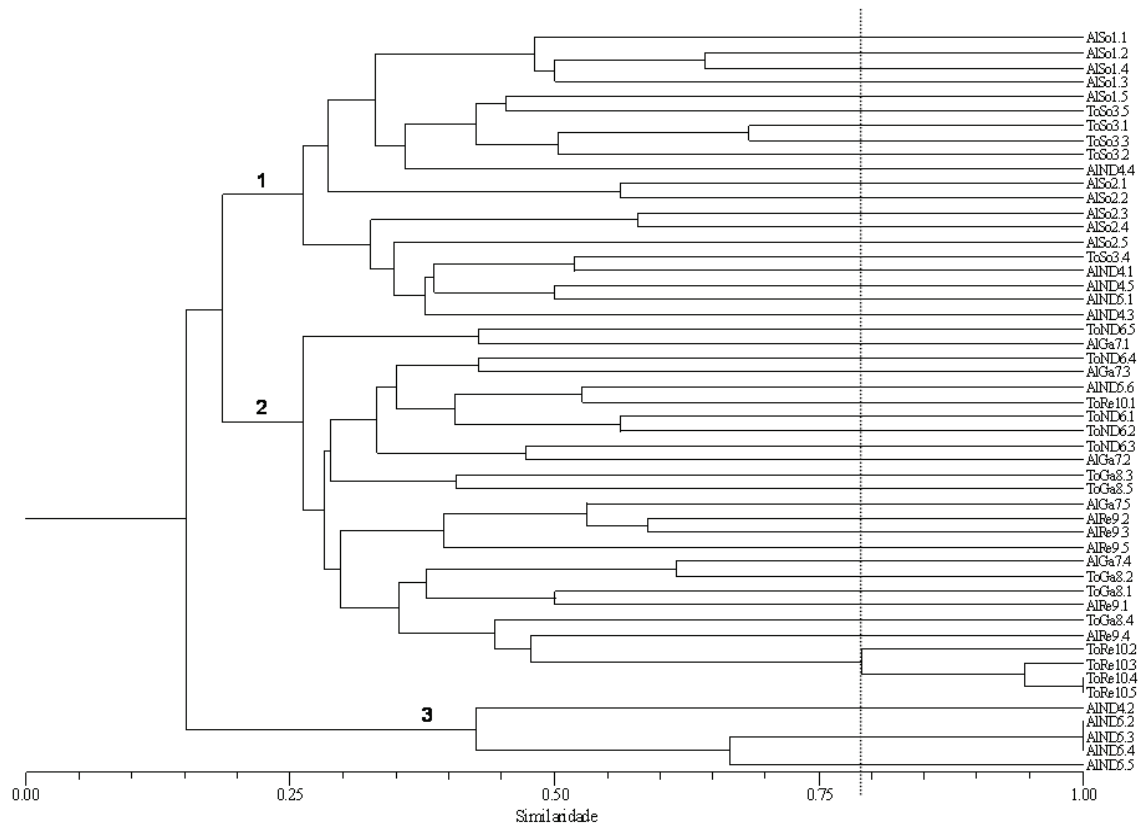

Figura 7 - Dendrograma construído a partir de dados de RAPD das dez populações de H. armigera coletadas em culturas de algodão e tomate em três localidades de Burkina Faso. Os códigos indicam: AlSo1, Algodão Soumousso; AlSo2, Algodão Soumousso; ToSo3, Tomate Soumousso; AlND4, Algodão N’Dorola; AlND5, Algodão N’Dorola; ToND6, Tomate N’Dorola; AlGa7, Algodão Gaoua; ToGa8, Tomate Gaoua; AlRe9, Algodão Réo; ToRe10, Tomate Réo. A linha pontilhada vertical indica o limite máximo de similaridade encontrado entre as populações de $H$. armigera.

A análise do dendrograma permitiu identificar três agrupamentos principais. Os indivíduos componentes do grupo 1 foram constituídos pelas duas populações coletadas em algodão (Soumosso), uma em tomate (Soumosso) e uma em algodão (N’Dorola). As populações constituintes do agrupamento 2 foram coletadas em tomate (N’Dorola), algodão (Gaoua), algodão (N’Dorola), tomate (Réo), tomate (Gaoua) e algodão (Réo). Esses dois agrupamentos apresentaram, entre si, aproximadamente $20 \%$ de similaridade genética. O agrupamento 3 foi composto 
apenas por uma população coletada em algodão em N'Dorola. Essa população apresentou em torno de 15\% de similaridade genética em relação aos grupos 1 e 2. Dos resultados analisados no dendrograma, observou-se que a similaridade genética entre as populações de $H$. armigera foi inferior a $80 \%$, indicando uma alta variabilidade genética entre os indivíduos que foram analisados neste estudo. A exceção ficou apenas para a população coletada em tomate (Réo) que apresentou índices de similaridade superiores a $80 \%$.

Para a confirmação e validação estatística dos resultados obtidos, realizou-se a seguir uma análise de variância molecular (AMOVA) para a determinação das fontes de variação genética que foram observadas nos agrupamentos no dendrograma.

A primeira análise consistiu em determinar a fonte de variação, quando todas as populações foram consideradas, independentemente da cultura e do local de coleta. Os dados de AMOVA revelaram que 24,26\% da variação observada eram provenientes de variações entre os grupos e que $75,74 \%$ eram de variações observadas dentro da população. Analisando-se posteriormente os indivíduos em relação às respectivas plantas hospedeiras, observou-se que, para a cultura de algodão, 23,53\% da variação obtida eram originárias de variações entre as populações e que, $76,47 \%$ estavam associadas a variações dentro das populações de H. armigera. Para a cultura de tomate, foram obtidos valores muitos semelhantes, ou seja, $23,48 \%$ de variação entre populações e $76,52 \%$, dentro da população.

A influência das localidades na distribuição das populações de H. armige$r a$ foi também analisada. Os resultados indicaram 9,07\% de variação era entre os grupos, $16,42 \%$ entre populações nos grupos e $74,51 \%$ dentro das populações. Das análises de similaridade genética e de AMOVA, observou-se uma elevada variabilidade genética dentro dos grupos analisados.

\subsection{Discussão}

Em virtude de seu amplo espectro de uso, a técnica de RAPD tem sido aplicada em diferentes níveis de estudo molecular de populações e espécies 
relacionadas de lepidópteras. Por exemplo, Fakrudin et al. (2004) empregaram 25 iniciadores de RAPD para analisar a variabilidade genética de populações de H. armigera ocorrendo em 12 áreas produtoras de algodão no sul da Índia. Os 497 fragmentos de RAPD produziram perfis eletroforéticos característicos para cada uma das populações, revelando elevada variabilidade genética entre elas. O dendrograma gerado revelou dois grupos principais com $22 \%$ de similaridade genética. Os autores sugerem que a alta variabilidade genética encontrada entre as populações de $H$. armigera poderia ser devido a barreiras topológicas e a temporais que poderiam influenciar no isolamento e no fluxo gênico entre as populações desse Lepidoptera.

Ainda, com relação à distância genética e ao fluxo gênico em lepidópteras, Sosa-Gómez (2004), utilizando a técnica de RAPD, analisou a variabilidade genética de A. gemmatalis ocorrendo em cinco localidades do Brasil e uma da Argentina. Os resultados de RAPD indicaram que existia uma grande diferença genética entre os indivíduos presentes nesses dois países. Entretanto, foi possível sugerir a possibilidade de eventos migratórios entre indivíduos presentes em localidades distantes.

Zhou et al. (2000) analisaram cinco populações de $H$. armigera ocorrendo em Israel e uma população ocorrendo na Turquia. Os autores utilizaram três iniciadores de RAPD que produziram 84 loci polimórficos que foram utilizados para estimar a relação filogenética entre essas populações. Os resultados de RAPD revelaram uma baixa distância genética, indicando um elevado fluxo gênico entre tais populações.

Para os indivíduos de $H$. armigera analisados nesse trabalho, observou-se uma elevada variabilidade genética dentro das populações, mas uma baixa variação entre elas. Isso sugere a possibilidade de eventos migratórios com consequente fluxo gênico entre populações de áreas distantes, tais como, N’Dorola, Gaoua e Réo, uma vez que os indivíduos coletados nessas três localidades se agruparam no mesmo clado do dendrograma. O mesmo resultado foi observado para as populações de Soumosso e N’Dorola. 
Além disso, a partir dos marcadores moleculares gerados por RAPD, foi possível o desenvolvimento de oligonucleotídios específicos para várias espécies de insetos. Essa estratégia foi aplicada por Agusti, De Vicente e Gabarra (1999) que desenvolveram iniciadores específicos para a detecção de $H$. armigera no intestino de possíveis predadores dessa espécie, como Dicyphus tamaninii (Heteroptera: Miridae). A partir de um fragmento de 1200 pb presente apenas em $H$. armigera e ausente em D. tamaninii, foi possível detectar a presença do inseto no intestino do seu respectivo predador.

Neste estudo, foram obtidos com o iniciador OPA-10 fragmentos de 500 pb e de 850 pb nos indivíduos de todas as populações de H. armigera. Esses fragmentos são alvos potenciais para o desenvolvimento de novos marcadores a serem amplificados em reações de PCR. A vantagem dessa estratégia é a obtenção de novas técnicas moleculares de detecção de pragas por métodos mais robustos que os marcadores RAPD.

\section{Conclusão}

A metodologia de extração foi adequada para a obtenção de DNA, como também os iniciadores de RAPD forneceram perfis moleculares para a identificação de H. armigera.

A técnica de RAPD mostrou-se útil na determinação de fragmentos de DNA comuns a todos os indivíduos nas dez populações analisadas, empregando-se apenas cinco iniciadores.

Observou-se elevada variabilidade genética dentro das populações dessa lepidóptera em Burkina Faso. Entretanto, houve baixa variação entre as populações.

Os dados gerados por RAPD sugerem processos migratórios com consequente fluxo gênico entre as populações de $H$. armigera. 


\section{Genetic variability analysis of Helicoverpa armigera (Lepidoptera: noctuidae) populations in crops of cotton and tomato}

\section{Abstract}

Helicoverpa armigera is a major polyphagous pest of worldwide distribution of crops of economic interest. The identification of this species by molecular markers is important to establish the genetic profile for the characterization and monitoring of populations of this Lepidoptera. The aim of this study was to establish a method for extraction of DNA from $\mathrm{H}$. armigera and determine electrophoretic profiles and analyze the genetic variability among populations of this insect pest. The five RAPD primers produced DNA fragments that showed a genetic similarity less than $80 \%$ among ten populations in the dendrogram that was generated. The results obtained from analysis of molecular variance (AMOVA) revealed that the highest source of genetic variation was the result of variability within each population. The causes that led to this high variability should be better studied in countries where the pest occurs.

Keywords: Molecular marker. RAPD. Tomato. Cotton.

\section{Referências}

AGUSTI, N.; DE VICENTE, M. C.; GABARRA, R. Development of sequence amplified characterized region (SCAR) markers of Helicoverpa armigera: a new polymerase chain reaction-based technique for predator gut analysis. Molecular Ecology, England, v. 8, n. 9, p. 1467-1474, Sept. 1999.

CIAMPI, A. Y.; MAGALHÃES, M. T. Q. Análise da variabilidade genética de três espécies arbóreas utilizando marcador molecular RAPD. Embrapa Cenargen, Brasília, n. 60, p. 1-8, 2001. Comunicado técnico.

FAKRUDIN, B. et al. Genetic variation of cotton bollworm, Helicoverpa armigera(Hübner) of south indian cotton ecosystem using RAPD markers. Current Science, India, v. 87, n. 12, p. 1654-1657, Dec. 2004.

FERREIRA, M. E.; GRATTAPAGLIA, D. Introdução ao uso de marcadores moleculares em análise genética. Brasília: EMBRAPA, 1998. 
HOLLOWAY, J. D.; BRADLEY, J. D.; CARTER, D. J. CIE Guides to insects of importance to man: I. Lepidoptera. London: CAB International, 1987.

JOHNSON, M. L.; ZALUCKI, M. P. Foraging behaviour of Helicoverpa armigera first instar larvae on crop plants of different developmental stages. Journal of Applied Entomology, Germany, v. 129, n. 5, p. 239-245, June. 2005.

MARTINS, E.S. et al. Análise da variabilidade genética de Anticarsia gemmatalis (Lepidoptera: noctuidae) por meio de marcadores moleculares RAPD. Brasília: Embrapa Recursos Genéticos e Biotecnologia, 2005. (Boletim de Pesquisa e Desenvolvimento 91).

NAGOSHI, R.N.; MEAGHER, R.L. Review of fall armyworm (Lepidoptera: Noctuidae) genetic complexity and migration. Florida Entomologist, United States, v. 91, n. 4, Dec. 2008.

PAULA, S. V. et al. Lepidópteras quarentenárias para o Brasil: subsídios para identificação e análise de risco de pragas. Brasília, DF: Embrapa Recursos Genéticos e Biotecnologia, 2004. 1 CD-ROM.

QUEIROZ, P. R. et al. Análise da variabilidade de uma população de Spodoptera frugiperda (J.E. SMITH, 1797) (Lepidóptera: Noctuidae) por meio de marcadores moleculares RAPD. Brasília: Embrapa Recursos Genéticos e Biotecnologia. 2004. (Boletim de pesquisa e desenvolvimento 75).

RHOLF, F. J. NTSYS-pc: Numerical taxonomy and multivariate system: version 2.9. New York: Applied Biostatistics, 1993.

SANNINO, L. Insect pests of tobacco. Informatore Fitopatológico, Bologna, v. 55, n. 2, p. 7-10, 2005.

SCHNEIDER, S.; ROESSLI, D.; EXCOFFIER, L. Arlequin ver. 2000: a software for populations genetics data analysis. Geneva: University of Geneva, 2000.

SHANOWER, T. G.; ROMEIS, J.; MINJA, E. M. Insect pests of pigeonpea and their management. Annual Review of Entomology, United States, v. 44, p. 77-96, January. 1999.

SOSA-GÓMEZ, D.R. Intraspecific variation and population structure of the velvetbean caterpillar, Anticarsia gemmatalis Hübner: 1818 (Insecta: Lepidoptera: Noctuidae). Genetics and Molecular Biology, Brazil, v. 27, n. 3, p. 378-384, September. 2004. 
Universitas: Ciências da Saúde, Brasília, v. 8, n. 1, p. 45-62, 2010
Paulo Roberto Queiroz, Luzia Helena Corrêa Lima

WILLIAMS, J. G. K. et al. DNA polymorphism amplified by arbitrary primers are useful as genetic markers. Nucleic Acids Research, England, v. 18, n. 22, p. 65316535, Nov. 1990.

ZHOU, X. et al. Population structure of the pestiferous moth Helicoverpa armigera in the Eastern Mediterranean using RAPD analysis. Heredity, England, v. 85, n. 3, p. 251-256, Sept. 2000.

\section{Agradecimentos}

Agradecemos ao Dr. Rémy Dabire, entomologista do INERA/ Farakoba em Bobo-Dioulasso, Burkina Faso, pelo envio das amostras de Helicoverpa armigera. 